\title{
Did the Easterlin Paradox apply in South Korea between 1980 and 2015? A case study
}

\author{
Michiel Slag $^{1,2} \cdot$ Martijn J. Burger $^{1} \cdot$ Ruut Veenhoven $^{1,2}$ (D
}

Received: 4 August 2018 / Accepted: 10 May 2019 / Published online: 20 May 2019

(c) The Author(s) 2019

\begin{abstract}
In 1974, Richard Easterlin presented data showing that there is no relationship between economic gro $_{\mathrm{w}}$ th and average happiness in the USA, but at the same time a higher personal income did go hand-in-hand with greater individual happiness in that nation. This phenomenon came to be known as the 'Easterlin Paradox'. Easterlin explains this pattern using the relative income theory, which holds that the positive effect of income increase is offset by: (a) adaptation to income change and (b) social comparison. There is discussion as to whether this pattern is universal and, in this context, Easterlin et al. (Proc Natl Acad Sci 107(52):22463-22468, 2010) claim that the enormous economic growth in South Korea over the last decade has not led to an increase in average happiness. In this paper, we report an empirical verification of this claim, using other data on South Korea. Contrary to Easterlin's claim, we found that South Koreans became happier over time and that the relative happiness theory did not apply in this case.
\end{abstract}

Keywords Easterlin Paradox $\cdot$ Income $\cdot$ Happiness $\cdot$ Life satisfaction

JEL classification $\mathrm{D} 60 \cdot \mathrm{I} 13 \cdot \mathrm{O} 109 \cdot \mathrm{O} 57 \cdot \mathrm{Z} 00$

\section{Introduction}

\subsection{The Easterlin Paradox}

In 1974, Easterlin presented data on the USA, showing that average happiness had not increased between 1946 and 1970, in spite of tremendous economic growth over these years, and that personal income was related to personal happiness in the United

Based on master thesis 'Easterlin Paradox or Easterlin Illusion? Some empirical tests' (Slag 2017).

Michiel Slag

michielslag@gmail.com

1 Erasmus Happiness Economics Research Organization EHERO, Erasmus University Rotterdam, Rotterdam, The Netherlands

2 Optentia Research Program, North-West University, Vanderbijlpark, South Africa 
States of America (USA), rich Americans being happier than their poorer compatriots. Easterlin observed that at one point in time, happiness varies directly with income both among and within nations, but over time an increase in income does not go handin-hand with an increase in happiness. Since economic growth translates to higher incomes, this finding seemed contradictory and came to be known as the 'Easterlin Paradox'. Easterlin explained this phenomenon assuming two cognitive mechanisms, 'adaptation' and 'social comparison', both of which will nullify the effect of income gains. Adaptation neutralizes the effect of extra income when aspirations rise at the same rate and social comparison keeps happiness at the same level; 'a riding economic tide lifts all boats' and any difference with references groups (the Jones's) remains the same. Together these notions are known as 'relative income theory'.

\subsection{Later research}

Easterlin's counter-intuitive finding has been the cause of considerable research on the effect of economic growth on happiness in nations, later studies being able to draw on a growing body of data, both for more countries and for longer time-series. The results of these later studies are mixed.

At the macro-level, several investigators have found a small positive effect of economic growth on average happiness in nations, e.g. Hagerty (2000), Hagerty and Veenhoven (2003), Stevenson and Wolfers (2008), Diener et al. (2013) and Veenhoven and Vergunst (2014). Easterlin disputes these findings (Easterlin 2005, 2016; Easterlin et al. 2010) and still argues that economic growth has not made us any happier.

Rather than just checking whether or not the Easterlin Paradox is true, several investigators have looked for the conditions under which it applies or not. At the macro-level of nations, Diener et al (2013) found that the effect of economic growth is more robust when measured using average income, than with GDP per capita, while De Neve et al. (2018) argue that the Easterlin Paradox can be partly explained by the asymmetric experience of positive and negative economic growth. Other studies have examined under which social circumstances GDP per capita growth goes hand-in-hand with increases in happiness. Oishi and Kesebir (2015) found that economic growth has increased average happiness only when economic growth is equally divided across the nation's population, while Mikucka et al. (2017) found that economic growth has a positive effect on subjective well-being when accompanied with decreasing income inequality and increasing social trust. Likewise, Bartolini et al. (2013) argue that if economic growth does not come with a reduction in (the quality of) social capital or relational goods, then happiness can well rise. Focusing specifically on the economic crisis, several studies have found that the negative impact of an economic crisis on subjective well-being can be alleviated by institutional and social trust (Helliwell et al. 2014), social capital (Gudmundsdottir 2013), and the presence of unemployment support programmes and employment protection legislation (Morgan 2018), and good quality of governance (Arampatzi et al. 2019). Many studies at the micro-level within nations have confirmed that people who earn a relatively high income tend to be happier than their less well earning fellow citizens. Follow-up studies have shown that income increases result in a 
positive change in an individual's happiness (Senik 2004; Frijters et al. 2004; Ferreri-Carbonell 2005; D'Ambrosio and Frick 2012; Vendrik 2013). Slag and Veenhoven (2018) provide a recent review of the available follow-up studies on this topic.

Micro-level studies on the effect of adaptation and social comparison on an individual's happiness have found both positive and negative coefficients. According to the relative income theory of Easterlin (1974), these effects should be consistently negative to cancel out the positive effect of income on happiness, but the data suggest that comparison can also boost happiness. This indicates that the Easterlin Paradox does not hold under all circumstances (Slag and Veenhoven 2018).

\subsection{Need for contextual focus}

So far, the data suggest that economic growth does not always work out on happiness in the same way; the Easterlin Paradox may apply in many cases, but it is not an 'iron law'; context dependency is more plausible. Economic growth is likely to involve various effects on happiness, and the balance of these effects is likely to vary across situations. If we have to choose whether to foster economic growth for the sake of human well-being, we must know in which conditions economic growth has affected happiness most and least.

In this regard, Easterlin's study shows that economic growth has not added to happiness in the USA since the end of World War II (Easterlin 1974, 1995). Later studies in Europe have shown that economic growth has added a little to average happiness in most European nations (Hagerty and Veenhoven 2003; Stevenson and Wolfers 2008). Since most research on the Easterlin Paradox has focused on Western nations, we are only limitedly informed about the effect of economic growth on happiness in East-Asia. The Easterlin Paradox seems to apply to China, in which rising GDP per capita has been accompanied by decreasing happiness levels (Brockmann et al. 2009; Easterlin et al. 2012; Li and Raine 2014).

On the contrary, Japan is a clear case in which there is a positive association between income increases and increases in average happiness (Stevenson and Wolfers 2008). Likewise, Lim et al. (2017) found no sufficient evidence of the existence of Easterlin Paradox in Taiwan and Malaysia in that they found a positive association between income and happiness over time, at both the micro- and macro-level.

\subsection{The case of South Korea}

In this paper, we considered the case of South Korea for which good data is available (cf. Sect. 2.1). Having examined at the macro-level effect of economic growth on average happiness, we then tested whether or not the relative income theory of Easterlin applied at the micro-level. South Korea is especially interesting, because this country is one of the fastest growing economies of this time with an average yearly growth of $7.3 \%$ since 1967 . Since it is likely that the effect of economic growth on average happiness is small, this effect will be better visible when there is large variation in GDP. Furthermore, median and average income in South Korea show more or less similar growth between 2006 and 2014, which indicates that economic 
growth in this country was equally divided in this era. Based on the World Values survey, Easterlin et al. (2010) concluded that there was no relationship between long-term growth and increases in happiness in South Korea. Using new macro- and micro-data, we will reassess.

The remainder of this paper is organised as follows: the data are described in Sect. 2, the analysis is discussed in Sect. 3, the results are presented in Sect. 4 and conclusions in Sect. 5.

\section{Data}

We used longitudinal data, both at the macro-level of the nation South Korea and at the micro-level of individual citizens. At the macro-level, we used trends in average happiness and average income and at the micro-level we used changes in individual happiness and individual income.

\subsection{Happiness}

The time-series data on average happiness in South Korea 1980-2010 that we used were taken from separate studies among representative samples of the general population. The follow-up data on individual happiness were taken from the Korean Income and Labour Panel Study (KLIPS), which gave us data from six yearly interviews from 2009 to 2014 inclusive.

\subsubsection{Time-series on average happiness in South Korea}

The data on average happiness in South Korea over the years were taken from the World Database of Happiness, which gathers findings on happiness in nations observed in different survey programs such as the World Values Survey, the Gallup World Poll. The following time-series of average happiness were used.

The World Values Survey (WVS), where respondents are asked questions on their subjective appreciation of life. The first question used was: 'taking all things together, would you say you are: very happy, quite happy, not very happy or not at all happy'. For further analysis, these answers are coded from 4 to 1 . The second question used was: 'All things considered, how satisfied are you with your life as-awhole now?' with answers possible between 10 (satisfied) to 1 (dissatisfied). Data taken from the WVS covered the years 1981, 1990, 1996, 2001, 2005 and 2012.

The Gallup World Poll (GWP), which includes the question 'suppose that the top of the ladder represents the best possible life for you and the bottom of the ladder the worst possible life. Where on this ladder do you feel you personally stand at the present time?' with answers ranging from 10 to 0 . The data taken from the Gallup World Poll covered the period of 2006-2015 and thus spanned one decade.

Two additional questions on happiness have been used in surveys in Korea: 'All things considered, how satisfied or dissatisfied are you with your life as-a-whole these days?' with answers ranging from 10 (very satisfied) to 0 (not satisfied). 
This question figured in surveys in 1980 and 2007. The second question is: 'Tell me how much you are satisfied or dissatisfied with your life as a whole?' with answers ranging from 1 (very dissatisfied) to 7 (very satisfied). This question was used in 1981 and 2001. These questions figured in different surveys, and their results are gathered in the World Database of Happiness (WDH), distributional findings on happiness in the general public in South Korea, questions type 122C and 122G (Table 1).

\subsubsection{Follow-up data on individual happiness and income in Korea}

For the micro-level data, data were obtained from the Korean Labour and Income Panel Study (KLIPS); the data from 2009 (wave 12) up to 2014 (wave 17) were used because the earlier waves only surveyed urban households and are therefore not representative of the general population of South Korea. This gave a total of 79,474 observations over a time span of 6 years. In KLIPS, the question relating life satisfaction is: 'Overall, how satisfied or dissatisfied are you with your life?' with answers ranging from very satisfied to very dissatisfied on a 5 step scale. Most studies used an ascending order for increased satisfaction, so the answer possibilities were reversed with very satisfied (5) and very dissatisfied (1). A descriptive account of the variables used is presented in Table 11 of the Appendix.

\subsection{GDP per capita}

The macro-level data on about GDP per capita in Korea over the years was taken from the OECD Database, and the micro-level data about changes in personal income were taken from the above-mentioned Korean Labour and Income Panel Study KLIPS.

Table 1 Overview of survey questions on happiness, used in South Korea 1981-2015

\begin{tabular}{|c|c|}
\hline Question & Years $^{\mathrm{a}}$ \\
\hline $\begin{array}{l}\text { 'Taken all things together, would you say you are: very happy, quite } \\
\text { happy, not very happy or not at all happy?' (WVS) }\end{array}$ & $1990 ; 1996,2001 ; 2005 ; 2012$ \\
\hline $\begin{array}{l}\text { All things considered, how satisfied are you with your life as-a-whole } \\
\quad \text { now? (WVS) }\end{array}$ & 1982, 1990; 2001; 2005; 2012 \\
\hline $\begin{array}{l}\text { Suppose the top of the ladder represents the best possible life for you } \\
\text { and the bottom of the ladder the worst possible life. Where on this lad- } \\
\text { der do you feel you personally stand at the present time? (GWP) }\end{array}$ & $\begin{array}{l}2006 ; 2007 ; 2008 ; 2009 ; 2010 ; \\
\quad 2011 ; 2012 ; 2013 ; 2014 \\
2015\end{array}$ \\
\hline $\begin{array}{l}\text { All things considered, how satisfied or dissatisfied are you with your life } \\
\quad \text { as-a-whole these days? (WDH) }\end{array}$ & $1980 ; 2001 ; 2007$ \\
\hline $\begin{array}{l}\text { Tell me how much you are satisfied or dissatisfied with your life as a } \\
\text { whole? (WDH) }\end{array}$ & $1981 ; 2001$ \\
\hline
\end{tabular}

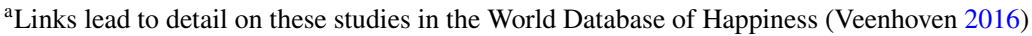




\section{Methodology}

The question whether economic growth is associated with average happiness increases in South Korea was answered using a macro-level trend analysis. The question as to whether comparisons with the income of compatriots have neutralized the effects of income growth on happiness is answered in a micro-level change analysis.

\subsection{Macro-level analysis}

We started with a simple bivariate presentation of the trends in economic growth and happiness in South Korea. Then, we did a more sophisticated multivariate analysis. In line with Stevenson and Wolfers (2008), we estimated the relationship between the average happiness and the natural logarithm of GDP per capita. This gave the following functional form:

$$
\text { Happiness }_{t}=\alpha+\beta \ln \mathrm{GDP}_{t}+\varepsilon_{t}
$$

where Happiness is the average happiness score in year $t$; $\ln \mathrm{GDP}_{t}$ is the natural logarithm of the real GDP per capita in year $t$ and $\varepsilon_{t}$ is the random error term; this error term captures the influence of other variables than real GDP per capita on happiness.

Since the number of observations for all measures of happiness was rather low, outliers may have a strong influence on the results. Therefore, an additional analysis was performed to address this issue. As mentioned in Sect. 2.1, there is data on five measures of happiness in South Korea that cover a relatively long-time period. Four of these measures have at least 20 years between the first and last observation, while the Gallup World Poll has a decade between the first and last observation.

In line with Stevenson and Wolfers (2008), we tested the Easterlin Paradox using a long difference approach. According to Easterlin, in the long term there should be no systematic difference in the average happiness in a country due to a difference in real GDP per capita. Regressing real GDP per capita on the first and last result of the different happiness measures enabled us to test this for South Korea. All the measures we used had different beginning and end years covering changes in the business cycle. Since all the measures were obtained using different questions to measure happiness with different scales of answer possibilities, we first standardized the answers to make them comparable.

Standardization of responses to answer scales of different lengths is accepted, only if the mean and standard deviation of the original data is also available. This is common practise when changing the length of Likert scales (Colman et al. 1997). As noted, different wordings were used for all the surveys; however, it was determined that for this study all measures of happiness and life satisfaction fell within the definition of happiness used by Veenhoven (1984). Standardization is not an optimal procedure, but this approach was preferred for comparability of measures and to take advantage of the different data available. 
Using the standardized scores, we took the first and last observations, and regress them against the log real GDP per capita in South Korea. This additional test gave the following functional form:

$$
\text { Happiness }_{i, t}=\alpha+\beta \ln \mathrm{GDP}_{t}+\varepsilon_{t}
$$

where Happiness ${ }_{i, t}$ is the standardized happiness scores of measure $i$ in year $t$; ln $\mathrm{GDP}_{t}$ is the natural logarithm of real GDP per capita in year $t$; and $\varepsilon_{t}$ is the random error term.

\subsection{Micro-level analysis}

At the micro-level, household income was regressed on happiness using the following formula:

$$
\text { Happiness }_{i, t}=\alpha+\beta \ln Y_{i, t}+\gamma X_{i, t}+d_{t}+\varepsilon_{t}
$$

where Happiness $s_{i, t}$ is an individual's happiness score in year $t, Y_{i, t}$ is an individual's household income in year $t, X_{i, t}$ is a set of control variables, $d_{t}$ is a year specific dummy, and $\varepsilon_{t}$ is the error term.

Ferrer-i-Carbonell and Frijters (2004) show that fixed effects models are to be preferred, since they control for time-invariant unobserved factors, such as personality traits. Since these factors have a large influence on an individual's happiness, it is important to control for this. This yields the following equation:

$$
\text { Happiness }_{i, t}=\alpha+\beta \ln Y_{i, t}+\gamma X_{i, t}+d_{t}+v_{i}+w_{i, t}
$$

where Happiness $s_{i, t}$ is an individual's happiness score in year $t, Y_{i, t}$, is an individual's household income in year $t, X_{i, t}$ is a set of control variables, $d_{t}$ is a year specific dummy, $v_{i}$ is the person time-invariant fixed effect error term, and $w_{i, t}$ is the timevariant error term.

Two variables were added to Eq. 4 to test for the effect of adaptation and social comparison. First, the lagged value of an individual's household income was included to test for adaptation, since individuals adapt to changes in income and thus the effect of changes in income on happiness decrease over the years. Lagged household income controls for previous income and thus for changes in household income. Second, the mean average income of an individual's reference group was added.

Many studies use income average income within a nation as their reference, but Goerke and Pannenberg (2015) have shown average income is not used as a reference in social comparison. Instead, direct colleges and friends form the most used social comparison group. Unfortunately, the available South Korean data do not inform us about the income of friends and colleagues. Therefore, we considered people with the same characteristics as the reference group, since friends and direct colleagues of an individual are often of about the same age as that person and have a similar education level. Creating reference groups is thus an arbitrary process. In this study, the reference group was specified as individuals who had in the same year the same education level, the same marital, employment and health status, and fell within the age range of -5 to +5 years of an individual's age. The more characteristics that are added to the above list, the fewer individuals there will be who share the 
same characteristics and the more the reference income will depend on only a handful of observations. This gave Eq. (5):

$$
\text { Happiness }_{i, t}=\alpha+\beta \ln Y_{i, t}+\gamma X_{i, t}+\beta_{1} \ln \bar{Y}_{i, j, t}+\beta_{2} \ln Y_{i, t-k}+d_{t}+v_{i}+w_{i, t}
$$

where Happiness $s_{i, t}$ is an individual's happiness score in year $t, Y_{i, t}$, is an individual's household income in year $t, X_{i, t}$ is a set of control variables, $Y_{i, t-k}$ is the income of individual $i$ during year $t-k$, where $k$ is the number of lags, $Y_{i, j, t}$ is mean income of reference group $j$ of individual $i$ during year $t, d_{t}$ is a year specific dummy, $v_{i}$ is the person time-invariant fixed effect error term and $w_{i, t}$ is the time-variant error term.

\section{Results}

At the macro-level, we observed a clear correlation between economic growth and average happiness in South Korea between 1980 and 2015. At the micro-level, we observed that South Koreans whose incomes grew became happier and this gain in happiness was not neutralized by adaptation or social comparison.

\subsection{Economic growth went together with a rise in average happiness in South Korea}

The macro-level analysis showed that economic growth mostly went hand in hand with a rise in average happiness in South Korea. This pattern of rising happiness appeared most clearly in the WVS data which cover the period 1980-2010. The GWP data showed a slightly different pattern with more fluctuations, but also showed a clear increase in happiness when looking at the total effect between 2006 and 2015. See the time graphs in Figs. 2-5 in Appendix.

Regression analysis was used to test formally the relationship between economic growth and the rise of average happiness in South Korea. In line with the findings of Easterlin et al. (2010), we do not find a significant correlation between the logarithm GDP per capita and life satisfaction measured in the World Value Survey. On the contrary, the relationship between the logarithm of real GDP per capita and the 4-scale measure of happiness from the World Values Survey and the 11-scale Cantril ladder from the Gallup World Poll. Hence, the evidence for the Easterlin Paradox at the macro-level in the South Koreans case seems to be limited (Table 2).

The long difference approach, discussed in Sect. 3, was used for further analysis. The standardized values of the first and last observation gave a more pronounced view of the results; for real GDP per capita and the natural logarithm of real South Korean GDP per capita, this effect was significant and positive, indicating a positive relationship between income and happiness on a macro-level in South Korea. The standardized coefficient was 0.06 for real GDP per capita (thousands of dollars) on happiness, and 0.898 for the natural logarithm of real GDP per capita. The standardized happiness scores for South Korea are provided in Fig. 1. All happiness scores indicating the first observations are found in the left bottom corner, the last observations are in the farright corner. This pattern indicated there was an increase in happiness across different 
Table 2 Macro-relationship between happiness and economic growth in South Korea

\begin{tabular}{llll}
\hline & Life satisfaction (WVS) & Happiness (WVS) & Life evaluation (Gallup) \\
\hline ln (GDP) & $0.536(0.280)$ & $0.166(0.029)^{* *}$ & $2.645(1.186)^{*}$ \\
Standardized coef- & 0.700 & 0.897 & 0.498 \\
ficient ln (GDP) & & & \\
Constant & Yes & Yes & Yes \\
$R^{2}$ & 0.491 & 0.805 & 0.248 \\
Period & $1982-2012$ & $1990-2012$ & $2006-2015$ \\
\hline
\end{tabular}

Robust standard errors are given in parentheses. $* p<0.10, * * p<0.05$ economic growth measured by real GDP per capita

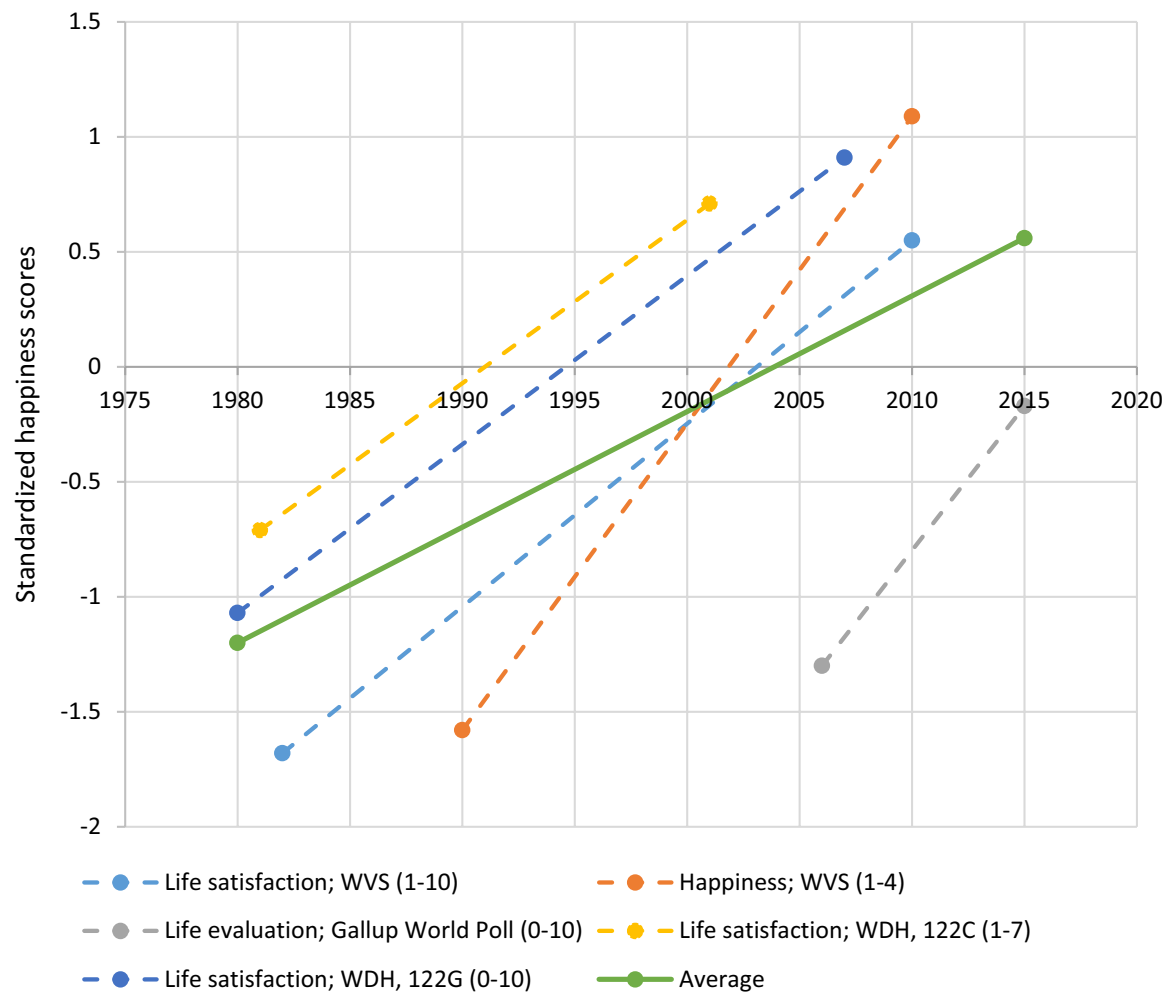

Fig. 1 Standardized happiness scores regressed against the real GDP/per capita in South Korea

measures and time periods, and thus, there was a positive relationship between economic growth and average happiness in South Korea (Table 3).

A limitation of this macro-approach focusing on only one individual country is that the positive trend in happiness and life satisfaction may be driven by other factors and the positive association between income and subjective well-being is spurious. Although the original paradox only referred to the lack of a positive correlation 
Table 3 Macro-relationship between happiness and economic growth in South Korea, long differences

\begin{tabular}{lll}
\hline & Standardized happiness & $R^{2}$ \\
\hline Real GDP/capita (log) & $0.898(0.347)^{* * *}$ & 0.442 \\
Real GDP/capita (1000 s) & $0.06(0.02)^{* * *}$ & 0.461 \\
\hline
\end{tabular}

Standard errors are given in parentheses. Asterisks denote statistical significance lower than or equal to the $* 10 \%$, **5\% and $* * * 1 \%$ level. Economic growth measured by real GDP per capita

and was not concerned with endogeneity problems, omitted variable bias poses a serious problem here (see Kaiser and Vendrik 2018). Adding additional control variables would be an option here, but given the small number of observations this can only be done to a limited extent. In addition, some control variables may mediate the effect of GDP per capita on happiness and should therefore not be included in the model. A country-panel approach (Layard et al. 2010; Sacks et al. 2010; Kaiser and Vendrik 2018) may help to alleviate these problems, but a further elaboration of this is beyond the scope of this paper.

\subsection{South Koreans whose income increased became happier: adaptation and social comparison did not neutralize that gain}

On the micro-level, the results are more pronounced: both life satisfaction and household income increased in South Korea over the period 2009-2014 (except for 2013). See Fig. 6 at Appendix.

Simple bivariate correlations between life satisfaction, current household income, earlier household income and reference group income are shown in Table 4. The zero-order correlation between life satisfaction and household income was 0.33 ; the zero-order correlations between earlier household income and life satisfaction and reference group income and life satisfaction were slightly smaller.

The results of the regression analysis of the relation between income and happiness in South Korea, based on Eqs. 3 and 4, are shown in Table 5. A random effects specification was used in Model 1 of Table 6, while a fixed effects specification was used in Model 2 of Table 5. As argued in Sect. 4.2, the results of models using fixed effects are considered to be most reliable. Models 3, 4 and 5 were extensions of Model 2 in which earlier household income and/or reference group income were added. Current household income was significantly positive across all different specifications.

Table 4 Correlation matrix life satisfaction and household income in South Korea

$\begin{array}{llll}\text { Life satisfaction } & \begin{array}{l}\text { Current house- } \\ \text { hold income }\end{array} & \begin{array}{l}\text { Earlier house- } \\ \text { hold income }\end{array} & \begin{array}{l}\text { Refer- } \\ \text { ence group } \\ \text { income }\end{array} \\ \end{array}$

\begin{tabular}{lllll}
\hline Life satisfaction & 1.000 & & & \\
Current household income & 0.329 & 1.000 & & \\
Earlier household income & 0.267 & 0.674 & 1.000 & \\
Reference group income & 0.287 & 0.552 & 0.484 & 1.000 \\
\hline
\end{tabular}




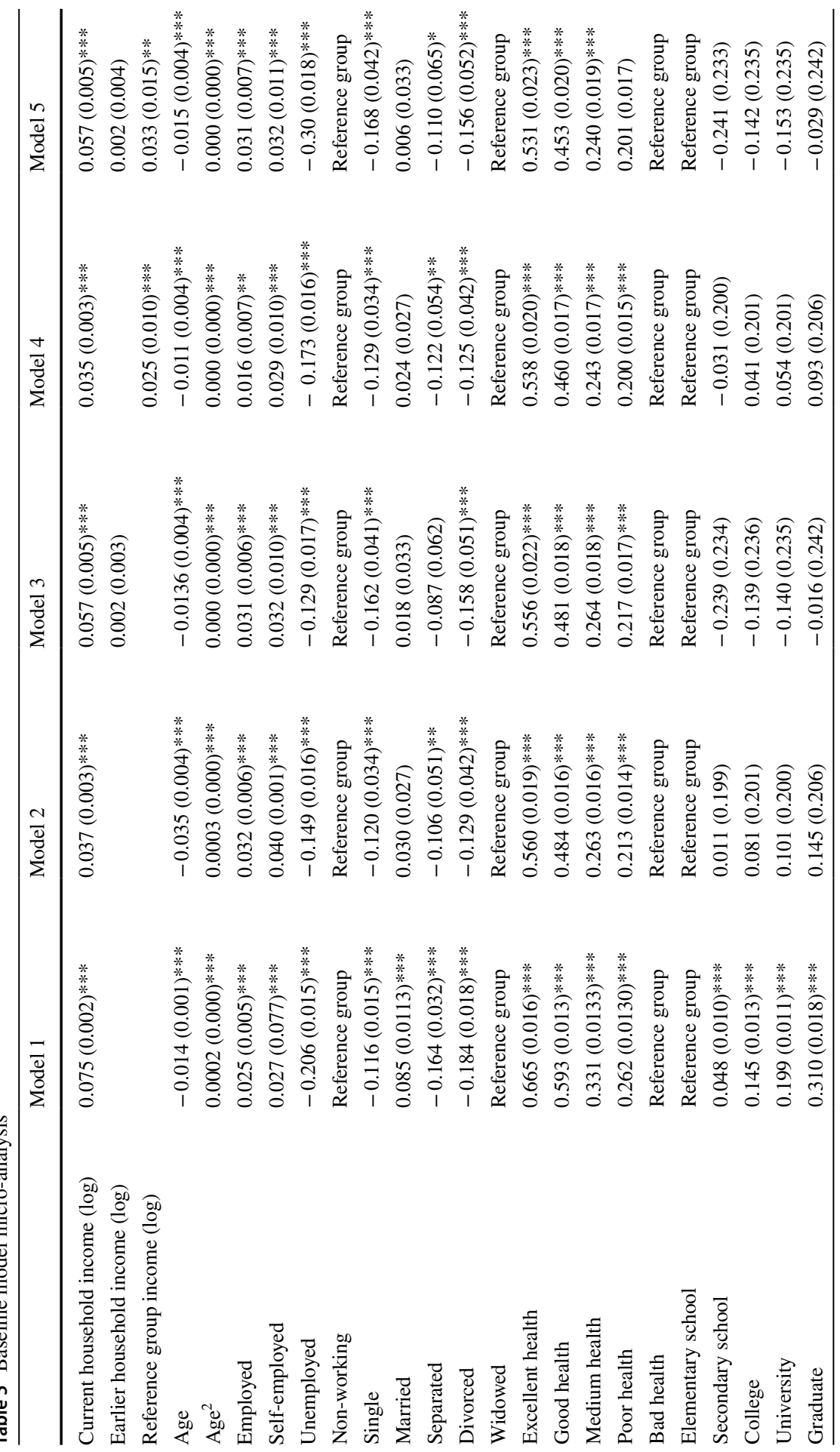




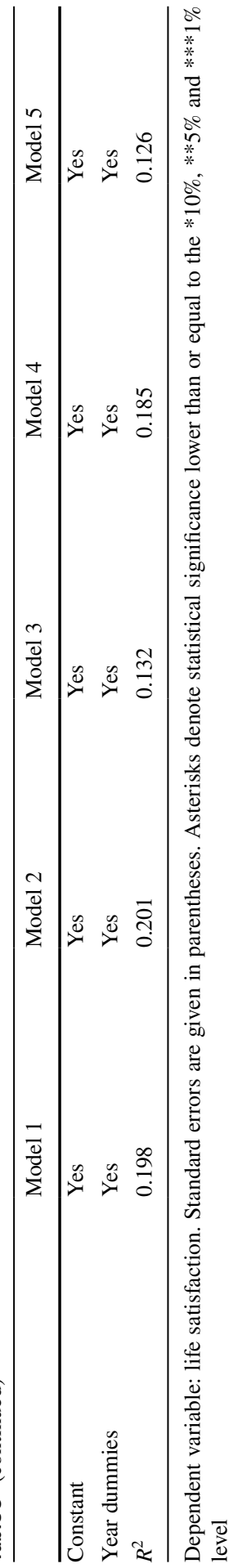

글 Springer 
Table 6 Estimates of the effects of life satisfaction on current household income: fixed effects estimation

\begin{tabular}{lcl}
\hline & No control variables & With control variables \\
\hline Life satisfaction $_{t-1}$ & $0.003(0.002)$ & $0.001(0.001)$ \\
Life satisfaction $_{t-2}$ & $-0.000(0.002)$ & $0.002(0.002)$ \\
Life satisfaction $_{t-3}$ & $0.001(0.002)$ & $0.002(0.002)$ \\
\hline
\end{tabular}

Dependent variable: log of current household income. Controls included: age, age squared, employment status, health status, relationship status and education level. Standard errors are given in parentheses. Asterisks denote statistical significance lower than or equal to the $* 10 \%, * * 5 \%$ and $* * * 1 \%$ level

Focusing on Models 3 and 5 in Table 5, it can be observed that the effect of earlier household income on life satisfaction, as proxy for the adaptation effect, was positive, but statistically insignificant. When we added more lags of an individual's household income to test for adaptation effects that lay further in the past, we saw that both the second and third lag of household income were negative and only significant at the $10 \%$ level(see Table 12 in the Appendix). Hence, past household income did not influence an individual's happiness; thus, no evidence for the adaptation effect was found for South Korea.

The effect of the reference group's income on life satisfaction was assessed in Models 4 and 5. This effect is only significant positive for this specification of the reference group. Other definitions of the reference group do not result in significant results of the reference group income on happiness in South Korea. See Table 13 in the Appendix. However, the effect of reference household income never becomes negative and statistically significant. Hence, there is limited evidence for social comparison effects in South Korea; instead rising incomes might give people hope for a better future.

\subsubsection{Endogeneity}

Fixed effects models tackle omitted variable bias by controlling for individual characteristics that remain (relatively) stably over time, such as personality traits. However, a potential problem still might be that an individual whose life satisfaction has increased recently is more likely to experience an increase in income since more satisfied individuals are generally more productive (De Neve and Oswald 2012; Oswald et al. 2015; Krekel et al. 2019). If there is a problem of reverse causality, we would expect that a higher level of life satisfaction makes a higher income later on more likely. Using different lags for life satisfaction (see also Chen and Van Ours 2018) and estimating our models with and without control variables, we do not find that a positive shock to life satisfaction is associated with an increase in income a year later. Also given that none of the effects are large, we conclude that reverse causality from life satisfaction to income is not a large problem.

\subsubsection{Similar pattern in subgroups}

Further analyses of the effects of household income, earlier household income and reference group income depending on age group, marital status or education 
level are provided in Tables 7, 8, 9 and 10. From Table 7, it can be observed that the effect of household income was larger among middle-aged individuals, but smaller for younger and older people. In addition, it appeared that there was a positive significant relationship between earlier household income and life satisfaction for the oldest age group. For middle-aged individuals (46-55), there found negative and significant association between earlier household income and life satisfaction, which provides some evidence for an adaptation effect. However, reference group income was not significant across all specifications.

Table 8 shows that the effect of household income is the largest among individuals who are separated, and the lowest for widowed individuals. This first finding should be interpreted with care since there was only a small number of separated individuals in the whole sample. A few outliers might influence the effect heavily. Furthermore, there was only some evidence for a social comparison effects for married individuals and some evidence for an adaptation effect for singles.

Tables 9 and 10 show that the effect of household income for the group with the lowest education level was smaller than that for all other groups. The effect of earlier household income was only positive significant at the $10 \%$ level for the lowest education level, while the effect of reference group income was only significant positive for the lowest education level and for university graduates.

\section{Discussion}

We found that the Easterlin Paradox did not apply in South Korea. Why has Easterlin concluded otherwise? What more can we learn about the effect of economic growth on happiness?

\subsection{Main findings}

This study showed that the Easterlin Paradox did not apply in South Korea between 1982 and 2015. On the macro-level, we found a positive relationship between economic growth and average happiness: 2 out of 3 measures of happiness provided significant results and the long difference approach clearly showed a highly positive significant relation between economic growth on average happiness. The latter result was most reliable because it included different measures of happiness across different time periods. On the micro-level, we found an even stronger link between happiness and income, while the effect of other people's income appeared to be positive, instead of negative. This result held across different specifications and subgroups of the population in South Korea. So, using our data taken from various sources reported in the World Database of Happiness, the relative income theory did not apply in the case of South Korea.

\subsection{Difference with Easterlin's analysis of this case}

Our results on the macro-level relationship contradict the claim made by Easterlin et al. (2010), that the high economic growth seen in South Korea has not made 


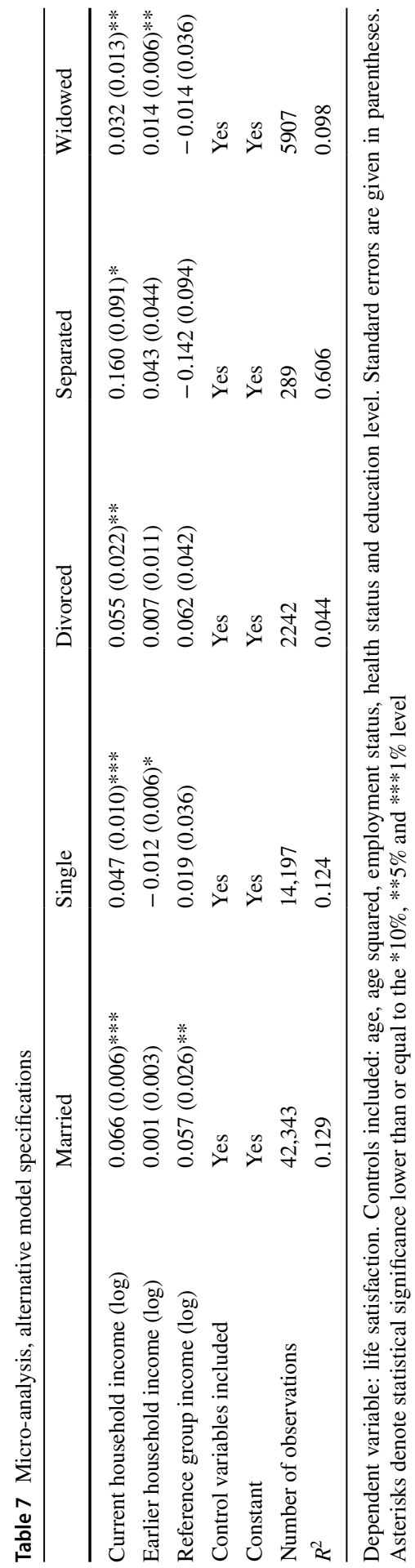




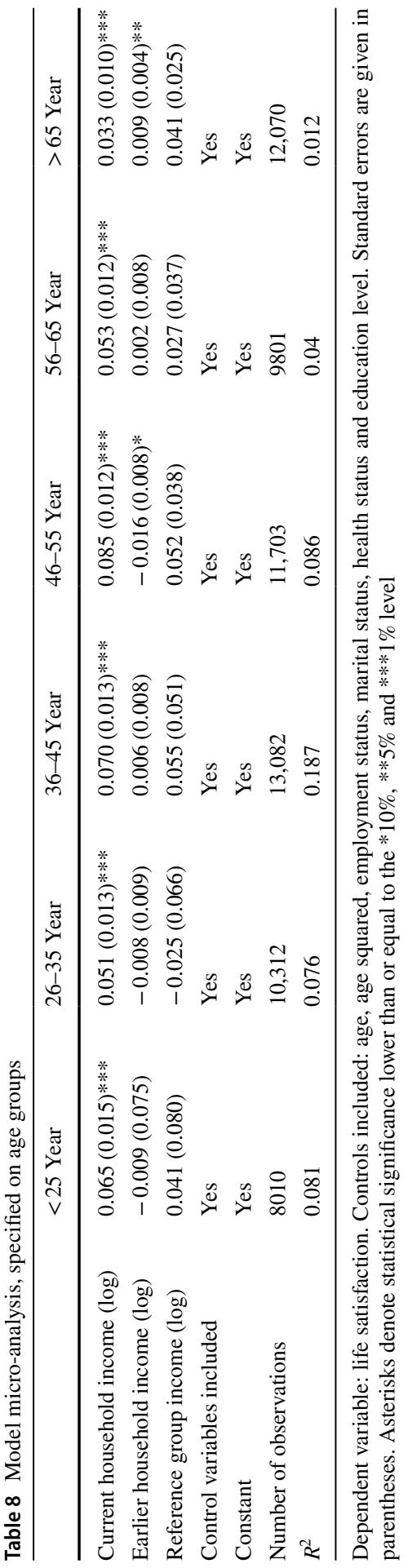




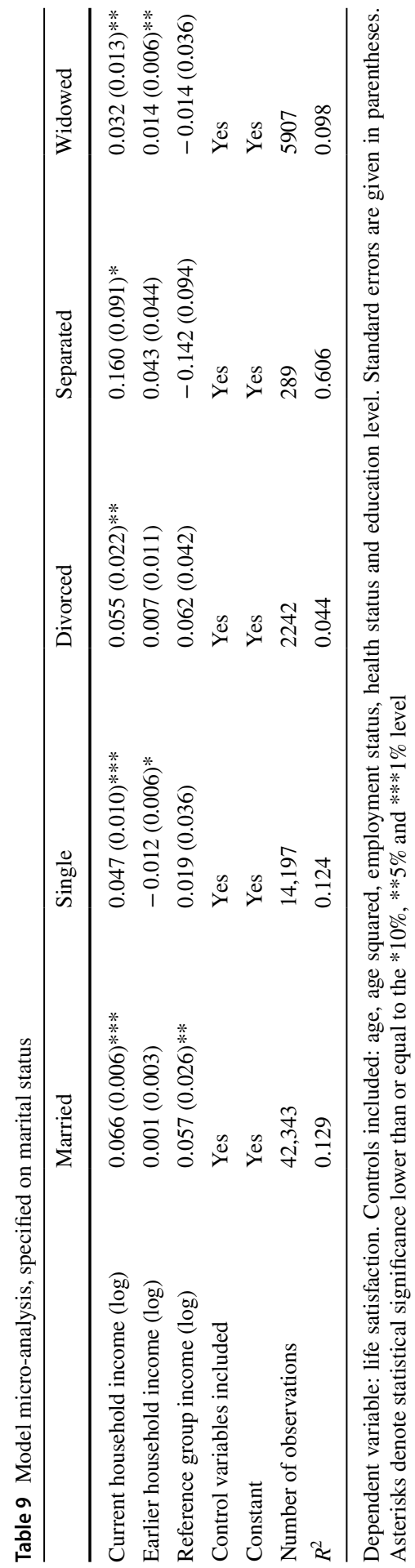




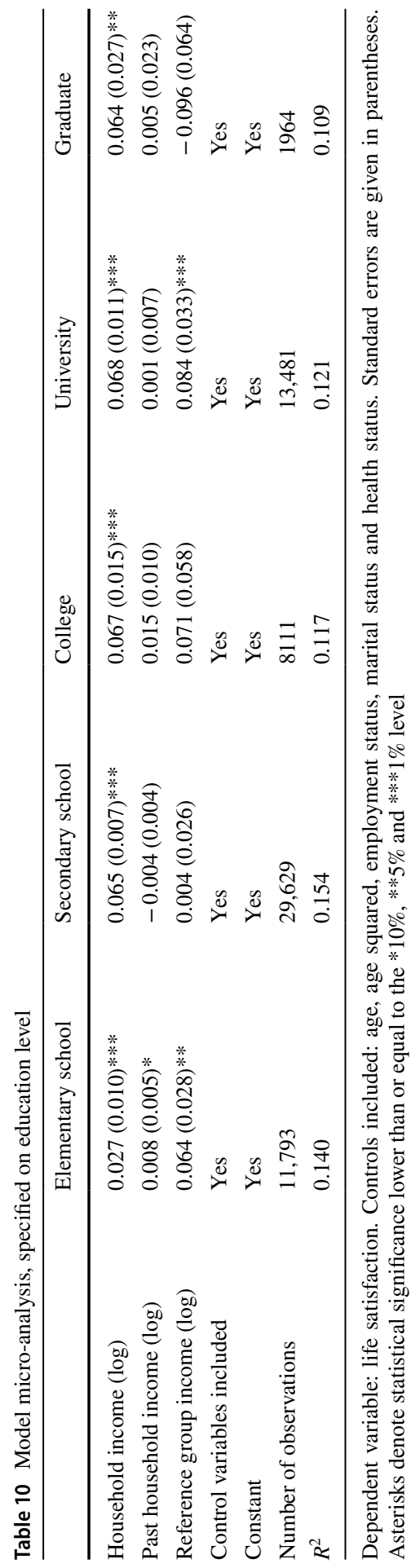


South Koreans any happier. Easterlin et al. (2010) based their claim only on the relationship between the life satisfaction scores in the World Values Survey 1980-2005 and economic growth, while we used a longer data period, more measures of happiness and more advanced techniques to establish the effect of economic growth on average happiness. We found a positive relationship between economic growth and average happiness in South Korea, which was statistical significant. So the difference is in the data, better data telling another story.

\subsection{Significance of statistical significance}

As we have seen from Table 2, the macro-level correlation between economic growth and rise of happiness was positive, but did not reach statistical significance. On the basis of this same finding, Easterlin et al. (2010) conclude that there is no relationship between economic growth and average happiness in South Korea. We have argued that using slightly different indicators and analyses gives a significant correlation.

How meaningful is statistical significance anyway in this discussion? Can we not just use effect sizes? 'Significance' is the probability that a correlation observed in an a-select sample will also exist in the population from which that sample was drawn. In this case, the 'population' is average happiness in South Korea in each of the 30 years between 1980 and 2010. The five observations of life satisfaction in the years 1990, 1996, 2001, 2005 and 2010 can hardly be considered as an a-select sample from that population, and the sample of only 5 cases is clearly too small to demonstrate significance of a small correlation. In short, this technique of significance testing is not well applicable in this case.

The unacknowledged limitations of significance testing have also clouded our view on cross-national tests of the Easterlin Paradox. In this case, the problem is not only that there is no a-select sample of nations, but more fundamentally, that the assumption of a 'population' of nations is misleading. As we will discuss in more detail below, effects of economic growth on happiness are likely to vary across contexts and looking for a general tendency is therefore fruitless. The question is not whether or not economic growth boosts happiness, but what are the conditions in which it boosts happiness in which conditions it does not.

\subsection{Further research}

A first task for future research is to overcome our present data limitations, in particular to use longer time-series, both at the macro-level and the micro-level. A second task is to explore causality in the relation between economic growth and happiness, a third task is to explore the conditions in which the balance of effects tends to be positive, neutral or negative and a fourth task is to identify the causal mechanisms.

\subsubsection{Longer time-series}

For our macro-level analysis, only a handful of observations was available per measure of happiness. More observations are necessary to draw more reliable 
conclusions. Future studies should incorporate different measures of happiness to increase reliability of the results.

On the micro-level, the KLIPS dataset has a relatively short span at present of only 6 years, making adaptation effects harder to study. This study should be repeated when a number of years have past to test whether the results we found still hold.

Additional over-time data on the macro- and micro-levels are required because, as Easterlin (2016) argues, the Easterlin Paradox is about the long-term trend relationship between economic growth and average happiness, and the focus is not on the short-term relationship.

\subsubsection{Contextual variation}

Economic growth in a country can affect the happiness of individuals in various ways, and the balance of effects is likely to differ across contexts. There is little point in searching for an average net effect, what we want to know is in what conditions economic growth adds to happiness and in what conditions does it not. Future research should therefore focus on separate country studies or look for contextual variation in world samples.

\subsubsection{Causal mechanisms}

We also want to know why effects of economic growth on happiness differ across times and places. In this paper, we checked one particular causal mechanism (social comparison) in one particular situation (South Korea 2009-2014). Future research should consider more of the mechanisms advanced in the literature on the Easterlin Paradox, such as a negative effect of economic growth on social capital in nations, which offsets the gain in happiness produced by economic growth (e.g. Bartolini et al 2013). Rather than demonstrating such effects in particular situations, this research should focus on differences across time and places.

\section{Conclusion}

Economic growth has added to happiness in South Korea since the 1980s. This illustrates that the Easterlin Paradox is not a general law, but rather a contextual phenomenon.

Open Access This article is distributed under the terms of the Creative Commons Attribution 4.0 International License (http://creativecommons.org/licenses/by/4.0/), which permits unrestricted use, distribution, and reproduction in any medium, provided you give appropriate credit to the original author(s) and the source, provide a link to the Creative Commons license, and indicate if changes were made.

\section{Appendix}

See the Figs. 2, 3, 4, 5, 6, 7 and Tables 11, 12 and 13. 


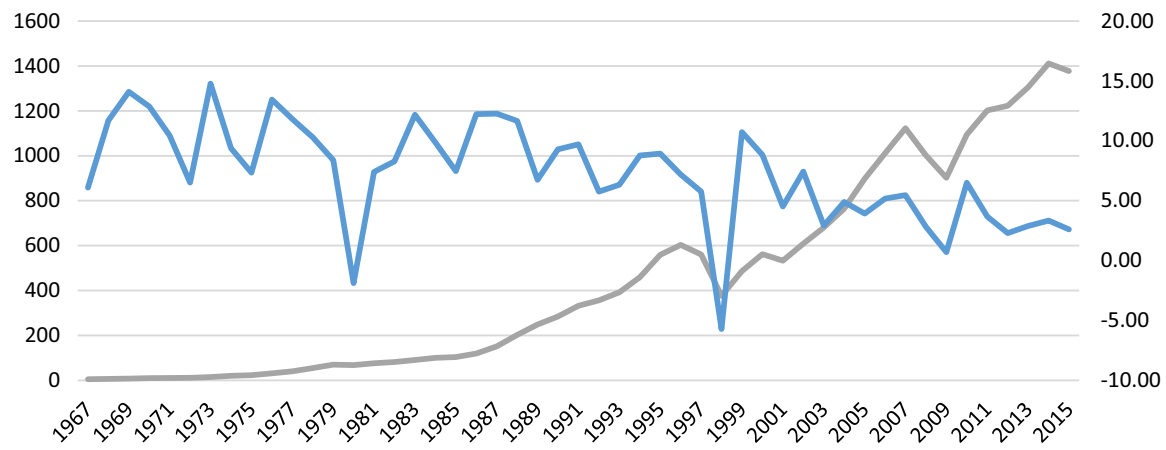

GDP (billion, current USD) $\quad$ GDP Growth

Fig. 2 GDP and GDP growth in South Korea. Source: OECD database

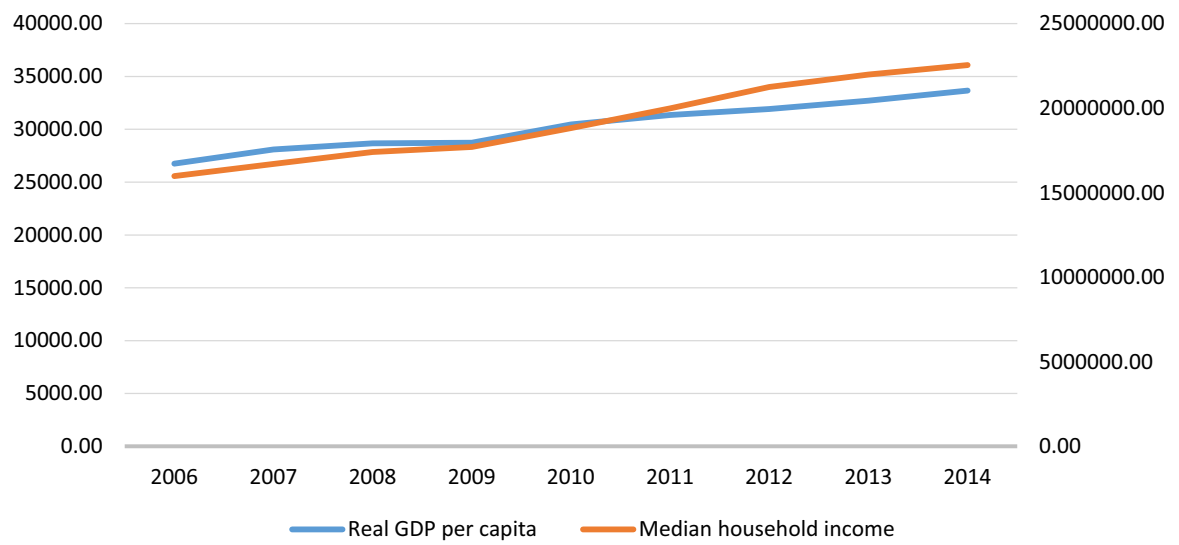

Fig. 3 Real GDP per capita and median household income. Source: OECD database

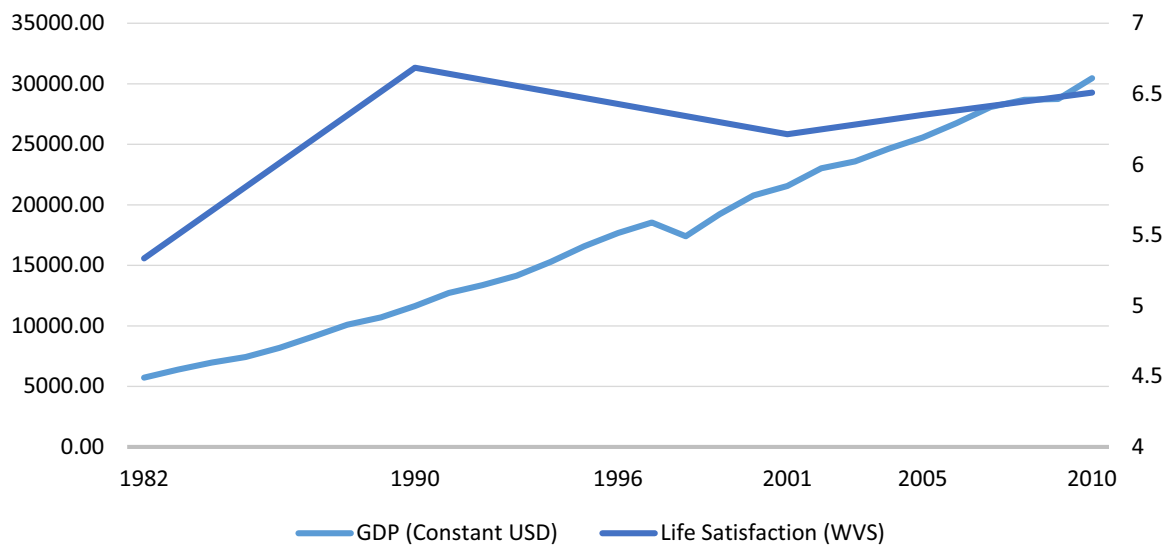

Fig. 4 Life satisfaction (WVS) and GDP/capita (USD) in South Korea. Source: World Values Survey, OECD database 
30000.00

25000.00

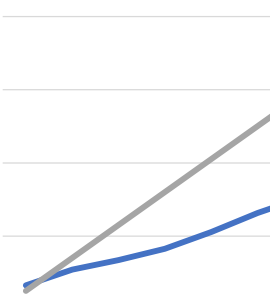

10000.00

20000.00

15000.00

5000.00

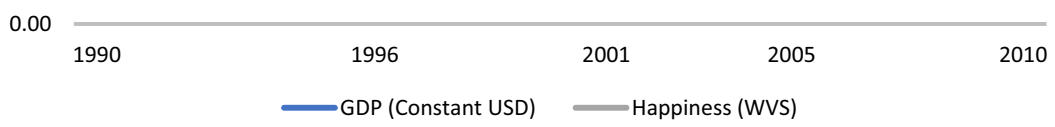

Fig. 5 Happiness (WVS) and GDP/capita (USD) in South Korea. Source: World Values Survey, OECD database

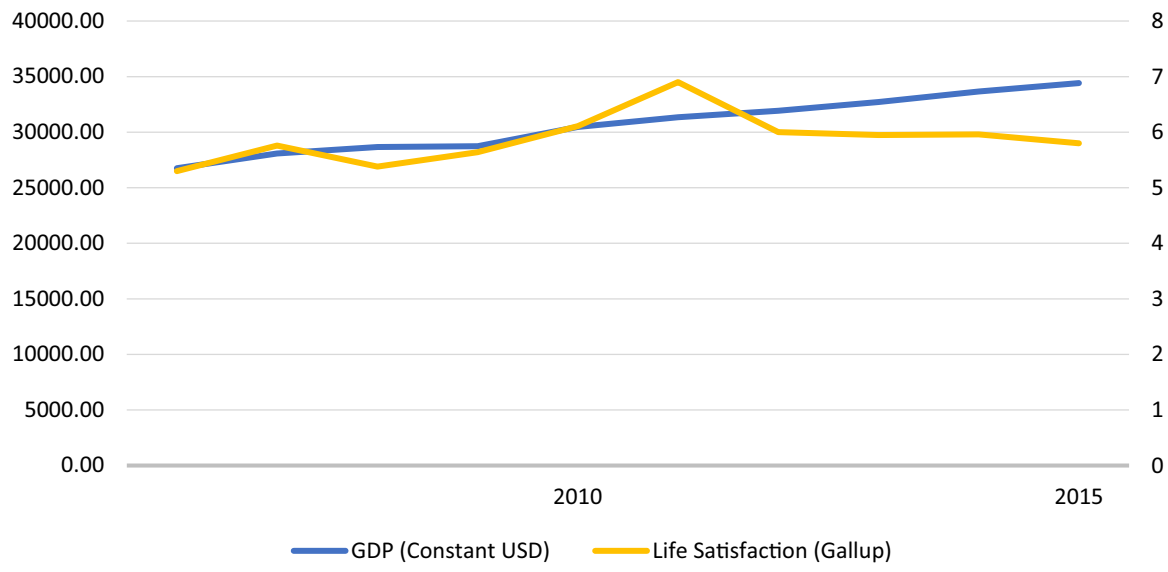

Fig. 6 Life evaluation (GWP) and GDP/capita (USD) in South Korea. Source: Gallup World Poll, OECD database 


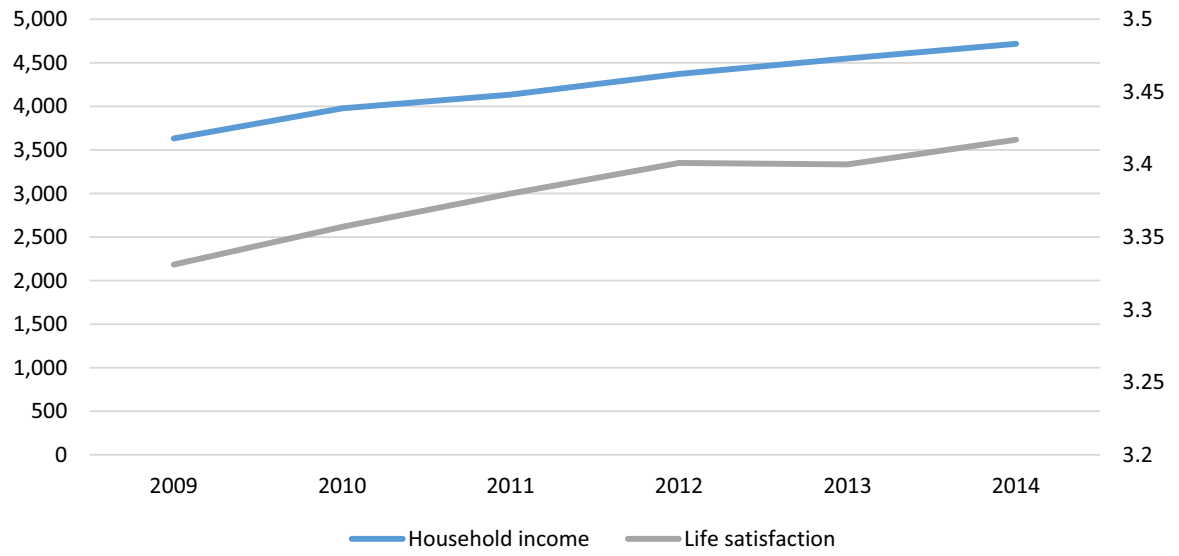

Fig. 7 Household income (SKW) and life satisfaction. Source: Korean Labour and Panel Income Studies

Table 11 Descriptive statistics micro-data

\begin{tabular}{lrrlll}
\hline Variable & Mean & SD & Min & Max & Observations \\
\hline Life satisfaction & 3.38 & 0.50 & 1 & 5 & 79,474 \\
Income & 4.22 & 3.70 & 0 & 121,500 & 79,474 \\
Reference group income & 4.24 & 1.60 & 2 & 332,695 & 78,987 \\
Log(income) & 797.73 & 1.13 & 0.6931472 & $1,170,767$ & 79,459 \\
Age & 47.23 & 17.97 & 15 & 100 & 79,474 \\
Employed & 0.28 & 0.45 & 0 & 1 & 79,474 \\
Self-employment & 0.09 & 0.29 & 0 & 1 & 79,474 \\
Unemployed & 0.02 & 0.13 & 0 & 1 & 79,474 \\
Non-working & 0.42 & 0.49 & 0 & 1 & 79,474 \\
Male & 0.48 & 0.50 & 0 & 1 & 79,474 \\
Single & 0.22 & 0.42 & 0 & 1 & 79,474 \\
Married & 0.65 & 0.48 & 0 & 1 & 79,474 \\
Separated & 0.01 & 0.08 & 0 & 1 & 79,474 \\
Divorced & 0.03 & 0.18 & 0 & 1 & 79,474 \\
Widowed & 0.09 & 0.29 & 0 & 1 & 79,474 \\
Excellent health & 0.05 & 0.21 & 0 & 1 & 79,474 \\
Good health & 0.51 & 0.50 & 0 & 1 & 79,474 \\
Medium health & 0.29 & 0.46 & 0 & 1 & 79,474 \\
Poor health & 0.12 & 0.33 & 0 & 1 & 79,474 \\
Bad health & 0.03 & 0.16 & 0 & 1 & 79,474 \\
Elementary school & 0.18 & 0.39 & 0 & 1 & 79,474 \\
Secondary school & 0.46 & 0.50 & 0 & 1 & 79,474 \\
College & 0.12 & 0.33 & 0 & 1 & 79,474 \\
University & 0.21 & 0.40 & 0 & 1 & 79,474 \\
Graduate school & 0.03 & 0.17 & 0 & 1 & 79,474 \\
\hline All & & 0 & 1 &
\end{tabular}

All variables relating income were measured in $10,000 \mathrm{SKW}$ 


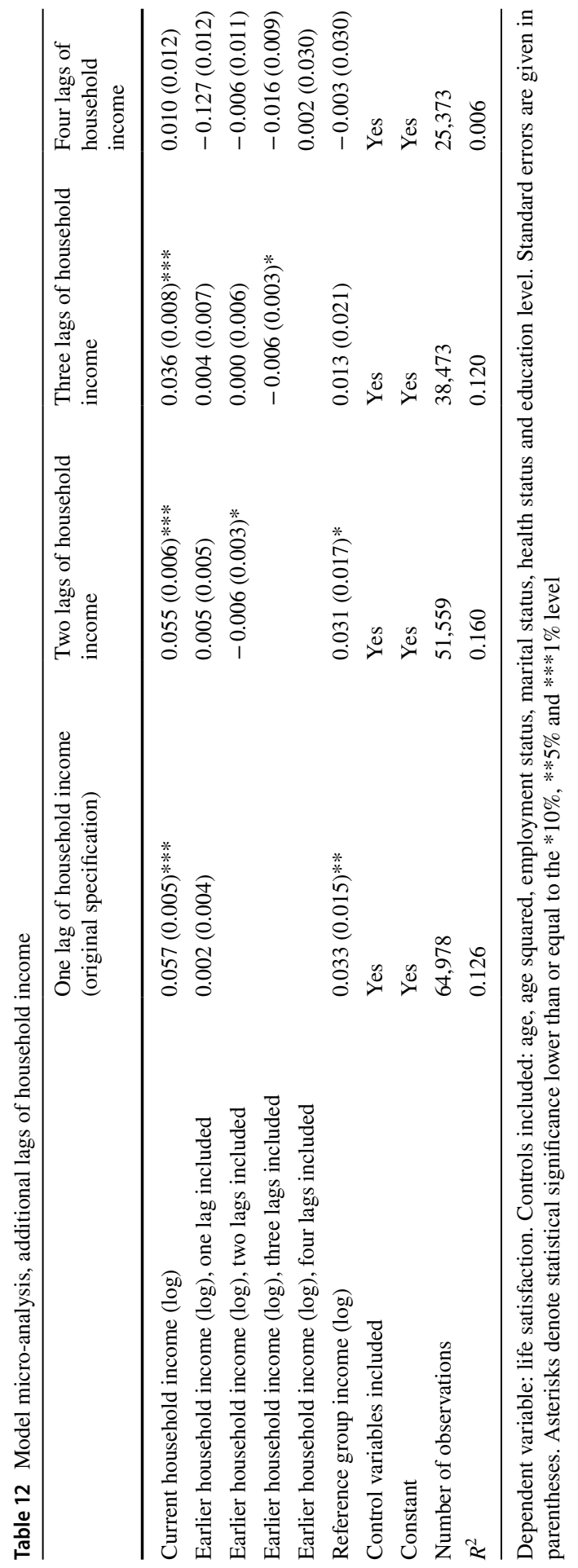




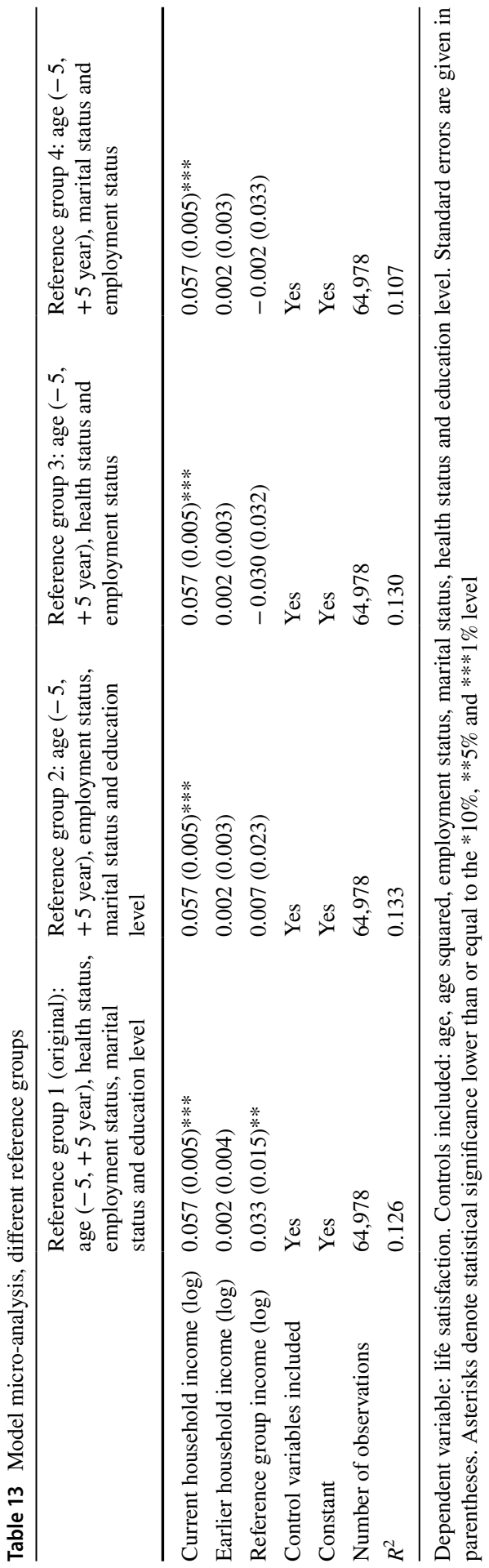




\section{References}

Arampatzi E, Burger MJ, Stavropoulos S, Van Oort F (2019) Subjective well-being and the 2008 recession in European Regions: the moderating effect of quality of governance. Int J Community Well Being (forthcoming)

Bartolini S, Bilancini E, Pugno M (2013) Did the decline in social connections depress Americans' happiness? Soc Indic Res 110(3):1033-1059

Brockmann H, Delhey J, Welzel C, Yuan H (2009) The China puzzle: falling happiness in a rising economy. J Happiness Stud 10(4):387-405

Chen S, van Ours JC (2018) Subjective well-being and partnership dynamics: Are same-sex relationships different? Demography 55(6):2299-2320

Colman AM, Norris CE, Preston CC (1997) Comparing rating scales of different lengths: equivalence of scores from 5-point and 7-point scales. Psychol Rep 80(2):355-362

D'Ambrosio C, Frick JR (2012) Individual wellbeing in a dynamic perspective. Economica 79(314):284-302

De Neve JE, Oswald AJ (2012) Estimating the influence of life satisfaction and positive affect on later income using sibling fixed effects. Proc Natl Acad Sci 109(49):19953-19958

De Neve JE, Ward G, De Keulenaer F, Van Landeghem B, Kavetsos G, Norton MI (2018) The asymmetric experience of positive and negative economic growth: global evidence using subjective wellbeing data. Rev Econ Stat 100(2):362-375

Diener E, Tay L, Oishi S (2013) Rising income and the subjective well-being of nations. J Pers Soc Psychol 104(2):267

Easterlin RA (1974) Does economic growth improve the human lot? Some empirical evidence. Nations Househ Econ Growth 89:89-125

Easterlin RA (1995) Will raising the incomes of all increase the happiness of all? J Econ Behav Organ 27(1):35-47

Easterlin RA (2005) Feeding the illusion of growth and happiness: a reply to Hagerty and Veenhoven. Soc Indic Res 74(3):429-443

Easterlin RA (2016) Paradox lost? In: USC-INET research paper (16-02)

Easterlin RA, McVey LA, Switek M, Sawangfa O, Zweig JS (2010) The happiness-income paradox revisited. Proc Natl Acad Sci 107(52):22463-22468

Easterlin RA, Morgan R, Switek M, Wang F (2012) China's life satisfaction, 1990-2010. PNAS 109:9775-9780

Ferrer-i-Carbonell A (2005) Income and well-being: an empirical analysis of the comparison income effect. J Public Econ 89(5):997-1019

Ferrer-i-Carbonell A, Frijters P (2004) How important is methodology for the estimates of the determinants of happiness? Econ J 114(497):641-659

Frijters P, Haisken-DeNew JP, Shields MA (2004) Money does matter! Evidence from increasing real income and life satisfaction in East Germany following reunification. Am Econ Rev 94(3):730-740

Goerke L, Pannenberg M (2015) Direct evidence for income comparisons and subjective well-being across reference groups. Econ Lett 137:95-101

Gudmundsdottir DG (2013) The impact of economic crisis on happiness. Soc Indic Res 110(3):1083-1101

Hagerty MR (2000) Social comparisons of income in one's community: evidence from national surveys of income and happiness. J Pers Soc Psychol 78(4):764

Hagerty MR, Veenhoven R (2003) Wealth and happiness revisited-growing national income does go with greater happiness. Soc Indic Res 64(1):1-27

Helliwell JF, Huang H, Wang S (2014) Social capital and well-being in times of crisis. J Happiness Stud 15(1):145-162

Kaiser C, Vendrik M (2018) Different versions of the Easterlin Paradox: New evidence for European countries. In: GSBE research memoranda, No. 026

Korean Income and Labour Panel Study (KLIPS) (2017) https://www.kli.re.kr/klips_eng/index.do

Krekel C, Ward G, De Neve JE (2019) Employee well- being, productivity and firm performance: evidence and case studies. In: Global happiness council, global happiness and well-being policy report 2019. pp 73-94 
Layard R, Mayraz G, Nickell SJ (2010) Does relative income matter? Are the critics right? In: Diener E, Helliwell J, Kahneman D (eds) International differences in wellbeing. Oxford University Press, Oxford, pp 139-165

Li J, Raine JW (2014) The time trend of life satisfaction in China. Soc Indic Res 116:409-427

Lim H-E, Shaw D, Liao P-S (2017) Revisiting the income-happiness paradox: the case of Taiwan and Malaysia. Inst Econ 9(4):53-69

Mikucka M, Sarracino F, Dubrow JK (2017) When does economic growth improve life satisfaction? Multilevel analysis of the roles of social trust and income inequality in 46 countries, 1981-2012. World Dev 93:447-459

Morgan R (2018) Labor market policy and subjective well-being during the great recession. Working Paper, Minerva Schools at KGI

Oishi S, Kesebir S (2015) Income inequality explains why economic growth does not always translate to an increase in happiness. Psychol Sci 26(10):1630-1638

Oswald AJ, Proto E, Sgroi D (2015) Happiness and productivity. J Labor Econ 33(4):789-822

Sacks DW, Stevenson B, Wolfers J (2010) Subjective well-being, income, economic development and growth (No. w16441). National Bureau of Economic Research

Senik C (2004) When information dominates comparison: learning from Russian subjective panel data. J Public Econ 88(9):2099-2123

Slag MRA (2017) 'Easterlin paradox' or 'Easterlin illusion'? Some empirical tests. Erasmus University Rotterdam, School of Economics, Master Policy Economics. Supervisor: Prof. dr. Ruut Veenhoven

Slag MRA, Veenhoven R (2018) 'Easterlin paradox' or 'Easterlin illusion? Systematic review of research findings. In: Paper under review

Stevenson B, Wolfers J (2008) Economic growth and subjective well-being: reassessing the Easterlin paradox (No. w14282). National Bureau of Economic Research

Veenhoven R (1984) Conditions of happiness. Kluwer Academic Publishers, Dordrecht

Veenhoven R, Vergunst F (2014) The Easterlin illusion: economic growth does go with greater happiness. Int J Happiness Dev 1(4):311-343

Veenhoven R (2016) World database of happiness. Erasmus University Rotterdam, the Netherlands. http://worlddatabaseofhappiness.eur.nl. Accessed on 30 December 2016

Vendrik MC (2013) Adaptation, anticipation and social interaction in happiness: an integrated error-correction approach. J Public Econ 105:131-149

Publisher's Note Springer Nature remains neutral with regard to jurisdictional claims in published maps and institutional affiliations. 